\title{
Computer Games and English as a Foreign Language: Results of a Pilot Study
}

\author{
Emmanuel Fokides \\ ORCID: 00oo-0003-3962-0314 • ResearcherID: U-1848-2017 \\ Anna Foka \\ ORCID: 00oo-0002-2586-998X • ResearcherID: U-1895-2017 \\ University of the Aegean, Department of Primary School Education, Rhodes
}

Received 1 November 2017 16 November 2017 • Accepted 30 November 2017

\begin{abstract}
The study presents the results of a pilot project in which computer games were used for teaching English as a foreign language to primary school students. The target group was sixty fifth-grade primary school students, divided into three groups. The first group was taught conventionally using the textbook. In the second, a contemporary teaching method was used, but the instruction was not technologically enhanced. The third group of students used the computer games without the teacher's intervention. Data were collected by means of a questionnaire and evaluation sheets. The data analysis revealed that the learning outcomes from the use of games were - more or less - the same as in the other methods. Also, the attitude of students towards games was very positive. The results can be attributed to students' enjoyment, motivation, and positive attitude towards the use of games as well as to the teaching method. The results also lead to the need to examine ways that would allow digital games to be even more effective in the teaching of English as a foreign language.
\end{abstract}

Keywords: collaborative learning, computer games, EFL, Kodu.

\section{Introduction}

The educational systems are in a constant pressure to change so as to effectively prepare students to meet the challenges of the 21st century. Given that technology has penetrated all aspects of our lives, the education included, the instructional use of computers is a reality that slowly but steadily, shapes new teaching methods, redefines the existing ones, and also changes, the content and the context of courses (Larsen et al., 2012). An exception to the above is the teaching of English as a foreign language (EFL). Unlike other teaching subjects, the use of computers in the teaching of EFL is a reality for a number of years (Köksal, 2004). At the same time, new tools, as well as innovative uses of existing ones, provide new perspectives on how to significantly increase students' motivation (Pim, 2013) and make the EFL teaching more interesting and effective (Morris, 2011; Macaro, Handley \& Walter, 2012).

Among these tools are computer games. It is more than obvious that games play a central role in children's lives. There is also a consensus in the literature that games can play an

(C) Authors. Terms and conditions of Creative Commons Attribution 4.0 International (CC BY 4.0) apply. Correspondence: Emmanuel Fokides, 1 Dimokratias str., 85132, Rhodes, Greece. E-mail: fokides@aegean.gr. Tel.: +302241099238. 
important role in education (e.g. Prensky, 2001a). Game-based learning (GBL) (Prensky, 2001b) can be applied in all levels of education and in almost all subjects. GBL's supporters believe that through games (digital or analog) most of the learning objectives can be achieved and that they have a significant impact on students' interest and motivation for learning (e.g., Bottino, Ferlino, \& Tavella, 2007; Ke, 2008; Papastergiou 2009).

- Games are used in many teaching subjects.

- The computer games were used without the teacher's intervention.

- The results of the project were mixed.

- Highly possitive attitudes towards the use of computer games were noted.

- Computer games can be used in EFL teaching.

Taking into account the above, it was decided to examine whether computer games can support the teaching of EFL in mainstream primary school settings. Towards this end, a pilot project was designed and implemented, the results of which are presented in the coming sections. The paper is organized as follows. First, a brief review of the literature on GBL and on the use of computer games in EFL is presented, followed by the project's methodology and results. Subsequently, results are discussed and the conclusion completes the work.

\section{Digital games in teaching}

Nowadays, computer games are used by the majority of children and teenagers for their entertainment (Ofcom, 2013). Computer games also have an impact in education, to such an extent that Prensky (2004) claimed that they are the most powerful learning tools. Indeed, over the past twenty years, there is a surge in research in GBL (e.g., Felicia, 2012; Gee, 2014; Ke, 2009; Prensky, 2007; Squire, 2005). One of the main arguments for using computer games in teaching is that they provide experiences in environments that are rich, sophisticated, interactive, and have similarities with real-life conditions. Therefore, the learning experience, which is considered to be the basis for the construction of knowledge, is not simply transmitted but it is the result of reflection and interaction with the (game) environment (Braghirolli, Ribeiro, Weise \& Pizzolato, 2016). In addition, students are encouraged to explore and experiment, which leads to the discovery of new concepts and strategies (Kirriemuir, 2002). Another important feature of computer games is that they provide immediate feedback; students can quickly see the results of their actions or if they answered correctly to a question (Prensky, 2001a). Moreover, students pay more attention to a learning activity when it occurs within a game (Garris, Ahlers \& Driskell, 2002). Finally, it has been observed that when students play educational games, they tend to spend more time in trying to learn (Sandberg, Maris \& De Geus, 2011).

While computer games are considered to be particularly effective at younger ages (Prensky, 2001b), there is no common consensus in the literature regarding their exact impact on students' learning outcomes. Indeed, the results of the relevant studies are mixed with some researchers reporting improved learning outcomes, others reporting a negative impact, and others reporting no impact at all (e.g., Perrotta, Featherstone, Aston \& Houghton, 2013). On the other hand, most researchers agree that computer games have a positive impact on motivation, engagement, and problem-solving skills (e.g., Connolly, Boyle, MacArthur, Hainey \& Boyle, 2012).

Also, researchers suggested that learning with games has to be supported by effective instructional strategies (Egenfeldt-Nielsen, 2006) and a well-developed games' pedagogy (Ulicsak \& Williamson, 2010). This brings the discussion to the learning theories that frame the use of computer games. It is true that diverse learning theories embrace their use in teaching (Dondlinger, 2007; Wu, Chiou, Kao, Hu \& Huang, 2012). The ones based on behaviorism, view learning as an associative process, in which reinforcement plays an important role in changing the observed behavior. This perception is evident in many games, which seek to exercise concepts or 
skills with repetitive practices (Braghirolli et al., 2016; Kebritchi \& Hirumi, 2008). On the other hand, educational games based on constructivist perceptions, support learning through the active participation of players/students in the learning process. In this case, the main purpose of computer games is to achieve student-centered interactive experiences, that enable the construction of knowledge on students' own pace (Shute, Rieber \& Van Eck, 2011), thus, redefining the relationship between students and teachers (Becker, 2005).

Coming to the teaching of EFL, it should be noted that computer games were considered useful at the very early stages of the integration of computers in education. Indeed, Dickinson (1981), was among the first to describe specific methods for harnessing the potential of role-playing games and simulations. In general, computer games are used in a variety of ways in the teaching of all foreign languages. For example, Connolly, Stansfield and Hainey (2011) used alternative reality games for telling stories in English, where the action changed depending on the participants' choices. Larsen (2012), used computer games as the sole means of instruction, without the interference of an instructor. Yolageldili (2011), noted that computer games have a positive impact on the correct use of language, both in terms of grammar and listening comprehension. Sylven and Sundqvist (2012), found that games improved the linguistic ability of students and also the level of understanding of English. Good results were obtained regarding the vocabulary of students aged 15-16 years who played games designed for this purpose (Sundqvist \& Sylvén, 2014). Notably, these researchers proposed that computer games can be used even from younger students.

In general, the effectiveness of computer games in EFL teaching can be attributed to several factors. Firstly, they create a pleasant environment that reduces the stress that students feel when they learn a foreign language (Muhanna, 2012). They also provide opportunities to use the language in its natural context, particularly when it comes to multi-user online games (Benavides, 2001). Also, Escudeiro and Vaz De Carvalho (2013), argued that their effectiveness is because they enable users to learn from their own mistakes.

It is important to stress that most studies regarding the use of computer games in EFL teaching were based on games where the element of fun was second compared to the element of teaching. Therefore, it would be interesting to examine the results from the use of games where the element of fun is dominant. A second point that has to be noted is that the sample in the majority of studies was young teenagers and not primary school students. Thus, further studies are needed in order to examine whether computer games are equally effective to younger ages. Finally, in almost all studies that dealt with the use of computer games in EFL teaching and in mainstream school settings (primary or secondary), the games were used either as a supplementary material or in conjunction with an instructor. Therefore, it would be interesting to conduct a study in which teachers are eliminated or play a supportive role.

\section{Method}

Given that digital games present an interesting alternative method for teaching EFL to students, as presented in the preceding section, a project was designed and implemented in order to examine what the learning outcomes of such an endeavor might be, having as a target group fifth-grade primary school students (ages 10-11). The whole effort was based on the assumption that computer games can act as mediators between students and the learning material, allowing students to understand the subject through their own experiences, having control of their pace of learning, as the constructivist views dictate (Ertmer \& Newby, 2013). A quasi-experimental design, with one experimental and two control groups, was chosen because data from intact classroom groups were analyzed for their differences in their learning outcomes, as it will be further elaborated in the coming sections. 


\subsection{Research hypotheses}

On the basis of the above, the following research hypotheses were formed:

H1: Teaching EFL to primary school students with the use of computer games, produces learning outcomes that are similar to those of conventional teaching methods. teaching EFL.

H2: Students form positive attitudes regarding the use of computer games in the

\subsection{Sample and duration}

The target group was decided to be fifth-grade primary school students (ages 10-11). That is because: (a) the literature review, as presented in the "Digital games in teaching" section, revealed few studies have been conducted regarding the use of computer games for teaching EFL at younger ages, and (b) after an initial overview of this grade's school textbooks, a number of teaching units were identified that were deemed as ideal for turning them into computer games. All of the primary schools in the city of Rhodes, Greece were conducted, as well as the teachers who teach EFL in these schools, in order to locate schools having an adequate number of computers, as well as students who met the following criteria: (a) to have never used computer games during their teaching, (b) to reflect the spread of ability in a typical mixed ability Greek fifth-grade class, and (c) the mix of genders to reflect the ratio of boys and girls in a typical Greek primary school. In Creswell's terms, the sample was achieved by selecting "ordinary", "typical", and "accessible" cases (Creswell, 2012).

As a result, the initial sample consisted of sixty-six students coming from three fifthgrade classes of three different schools. In each class, a teaching method, described in the "Procedure" section, was randomly assigned. Prior to the beginning of the project, students' parents were informed of its purpose and objectives and their written consent for the participation of their children was obtained. Also, the participating teachers were briefed. The project lasted for three weeks (from mid-February to early March 2017), for a total of fifteen two-hour sessions (five in each class).

\subsection{Materials}

During meetings with the project's participating teachers and a more thorough review of students' EFL textbook, five units were selected for converting them into computer games. The theme in all of them was environmental awareness: (a) Unit 1 - Pollution, (b) Unit 2 - Meet recycling bins, (c) Unit 3 - What about electronics?, (d) Unit 4 - Do you love our planet?, and (e) Unit 5 - Air pollution.

For the development of the games (one for each unit), the programming environment of Microsoft's Kodu Game Lab (https://www.kodugamelab.com/) was used. Kodu is a programming environment designed exclusively for the rapid development of $3 \mathrm{D}$ games. It provides a very simple icon/tile-based visual programming language, which does not require prior knowledge of programming. Furthermore, it offers a library of ready-made cartoonish objects and characters and a set of manipulation tools to build the games' landscape. On the negative side, the developers have to develop their games using only Kodu's available media, since it does not allow the import and use of external media (e.g., 3D models, images, videos, and sounds).

It is important to stress that the games were not developed by a group of experts but by the participating teachers. Although one can argue that this resulted in games being "amateurish", it was important to examine the difficulties the educators face when they have to develop their own games/teaching material to be used by their students. A 30-hour intensive 
course/seminar was held since the teachers did not have any previous experience in using Kodu. In addition, they had at their disposal printed and audiovisual material for guiding them. Also, they were advised to follow Gee's guidelines for designing "good" educational games (Gee, 2009; 2005): (a) to provide simple control mechanisms, (b) the cognitive material to be clearly presented, (c) to provide compelling experiences for good learning, and (d) to allow users/learners to enact their own trajectories. Furthermore, they were asked to find ways of presenting the learning material in-game, because this was a prerequisite of the teaching methodology that was followed, as it will be further elaborated in the "Procedure" section.

It has to be noted that the teachers were able to come up with interesting ideas for overcoming the limitations imposed by Kodu (e.g., a limited number of objects and media) (Figures 1). On the other hand, it was observed that all games were, essentially, drill and practice applications. This observation will be further elaborated in the "Discussion" section.

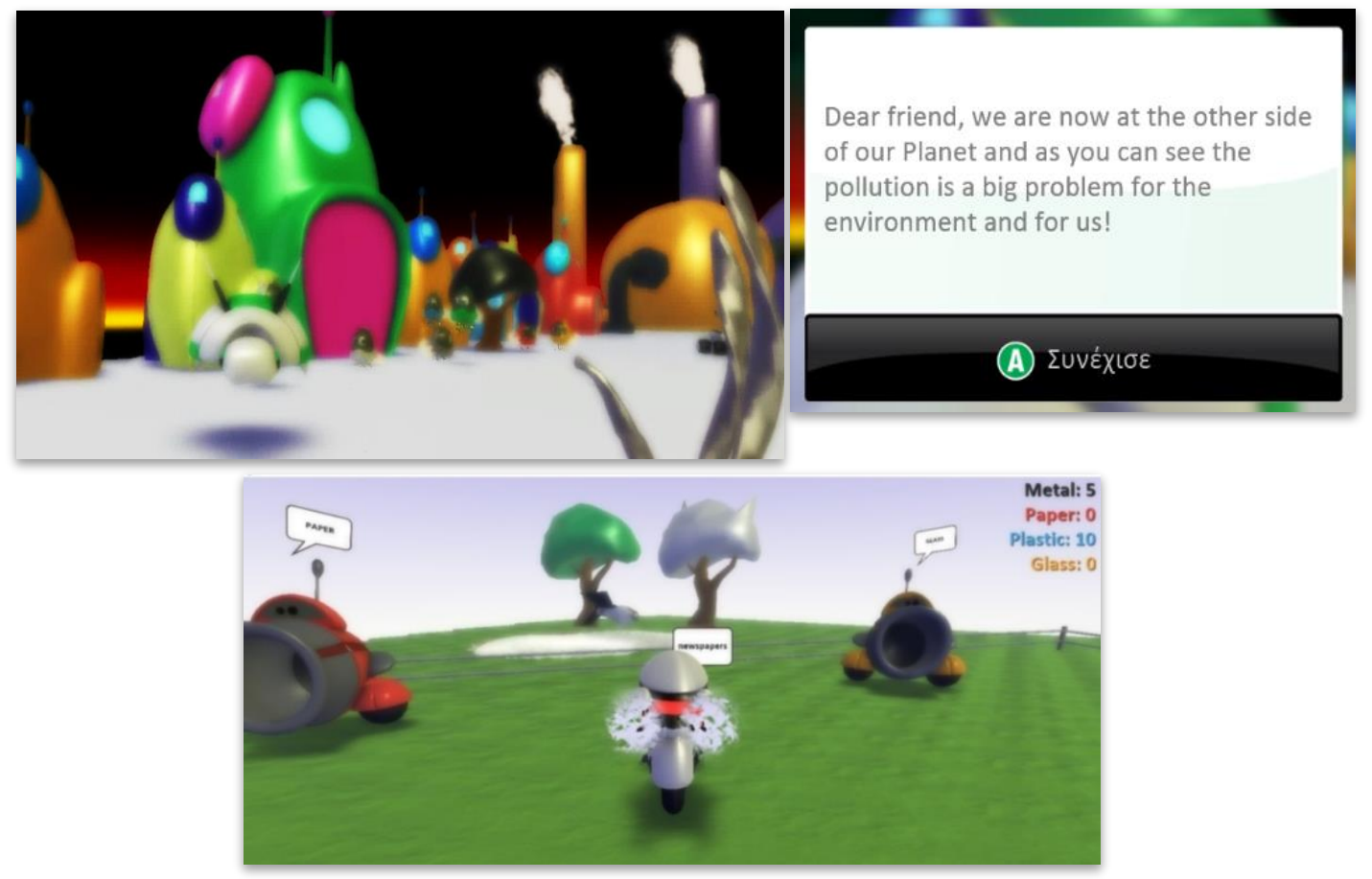

Figures 1. Screenshots from the games

Each game had a central level in which the learning material was presented and several smaller levels which were mini-games for allowing students to practice what they have learned. The texts and dialogues were exactly the same as in the school handbook. Also, all the necessary instructions, how to control the game, and what to watch out for, were written in English. This was done because it was considered important to enrich student's vocabulary and also familiarize them with the syntax of the language. Since it was important for students to listen to the pronunciation of the words and because Kodu does not allow the import of audio, video clips were recorded using Kodu and a screen capture software. In addition, these videos included the relevant theory and vocabulary. Students could access these videos after finishing playing the games. The design and development of the games and videos lasted for about four weeks (approximately 150 hours).

\subsection{Procedure}

As already mentioned, three groups of students participated in the study, coming from three different schools. In each group, a different teaching method was assigned. The first group 
was taught conventionally and only the school textbooks were used. The teacher made a short introduction regarding the unit he/she was about to teach, followed by examples and/or demonstrations (using the class's video projector). Next, students worked individually, by studying the relevant unit in the textbook and by solving the exercises. During this stage, the teacher's involvement was minimal; only when needed, he/she paused students work in order to provide guidelines and examples to the whole class. At the end of each session, the teacher and/or the students presented the solutions to the exercises and the students were asked to check whether their answers were correct. This teaching method is the prevailing one in Greek schools.

To the second group, the teaching method was based on the constructivist views for learning/teaching. After a short introduction by the teacher for the subject of each unit, students were divided into groups of four and studied the relevant unit (from the school textbook) and solved the exercises collaboratively. Discussions and the exchange of views were encouraged by the teacher, who constantly urged students to use English for communicating between themselves. The last phase of the instruction was dedicated in collaborative activities, which were designed so as to encourage the use of English (for speaking and writing). For example, in Unit 2 - Meet recycling bins, there was a team game which involved the use of cardboard for making recycling bins.

Finally, the third group of students was taught exclusively using the computer games; the school textbook was not used at all. Students were divided into pairs and each pair had at its disposal a computer, where they played the games and watched the related videos. The teacher simply provided assistance in case of technical problems. As in the previous group, discussions, and exchange of views in English were encouraged. As a result of the above, three groups of students were taught the same units, with the same duration. What differed was the teaching method.

\subsection{Instruments}

The main instruments used for collecting data was evaluation sheets (including a preand a delayed post-test). The pre-test was of particular interest because it is known that most students study English in private evening schools or are home tutored. Therefore, participants' knowledge level of English may considerably vary, and this could have had an impact on the study's results, leading to incorrect conclusions. The delayed post-test was administered about fifteen days after the end of the project and contained questions from all the units. Its purpose was to examine the sustainability of knowledge.

The evaluation sheets as well as the pre- and delayed post-tests, had Yes-No, fill-inthe-blanks, open-ended, and multiple-choice questions, which, for compatibility reasons, were the same (or similar) to the ones in the school textbook. It should be noted that, in addition to the above, translation of text from Greek into English and vice versa, as well as the writing of short sentences in English, were also included in the evaluation sheets.

One of the purposes of the study was to explore students' attitudes and perceptions on the use of computer games during their teaching. Thus, the second instrument that was used was a short questionnaire administered to students at the end of the project. It consisted of ten 5-point Likert-type questions (worded "Strongly Agree", "Agree”, "Neutral”, "Disagree" and "Strongly Disagree") and four open-ended questions. Scores were obtained by allocating numerical values to responses: "Strongly Agree" scored 5, "Agree" scored 4; "Neutral” scored 3; "Disagree" scored 2 and "Strongly Disagree" scored 1. The open-ended questions asked students to justify their views and opinions. 


\section{Results}

Students who were absent in one or more sessions were excluded from the analysis. Thus, the final sample size was sixty students, divided into three groups of twenty: (a) Group 1, students in the conventional teaching method, (b) Group 2, students in the constructivist teaching, and (c) Group 3, students who used the games. For obtaining quantitative data, the evaluation sheets (including the pre- and the delayed post-test) were graded on the basis of the number of correct answers. Mean scores and standard deviations per group of participants and per evaluation sheet are presented in Table 1.

Table 1. Means and standard deviations per group and per evaluation sheet

\begin{tabular}{|c|c|c|c|c|c|c|}
\hline & \multicolumn{6}{|c|}{ Groups } \\
\hline & \multicolumn{2}{|c|}{$\begin{array}{c}\text { Group } 1 \\
(N=20)\end{array}$} & \multicolumn{2}{|c|}{$\begin{array}{l}\text { Group } 2 \\
(N=20)\end{array}$} & \multicolumn{2}{|c|}{$\begin{array}{l}\text { Group } 3 \\
(N=20)\end{array}$} \\
\hline & $M$ & $S D$ & $M$ & $S D$ & $M$ & $S D$ \\
\hline Pre-test $(\max =30)$ & 22.25 & 4.75 & 18.68 & 7.13 & 20.68 & 4.76 \\
\hline $\mathrm{ES} 1(\max =25)$ & 22.05 & 2.63 & 19.05 & 4.52 & 21.70 & 3.85 \\
\hline $\mathrm{ES} 2(\max =20)$ & 18.05 & 2.19 & 15.23 & 4.30 & 18.38 & 1.91 \\
\hline $\mathrm{ES}_{3}(\max =32)$ & 29.90 & 2.90 & 25.65 & 7.36 & 31.25 & 1.25 \\
\hline $\mathrm{ES} 4(\max =20)$ & 17.40 & 4.11 & 14.85 & 4.34 & 17.60 & 3.02 \\
\hline $\mathrm{ES}_{5}(\max =20)$ & 17.00 & 3.08 & 15.55 & 2.40 & 13.90 & 3.08 \\
\hline Delayed post-test $(\max =35)$ & 30.80 & 5.00 & 28.40 & 6.24 & 32.40 & 3.09 \\
\hline
\end{tabular}

One-way ANOVA tests were to be conducted to compare the scores of the three groups in all tests, in order to determine if they had any significant differences. Prior to conducting these tests, it was checked whether the assumptions of ANOVA testing were met. It was found that: (a) all groups had the same number of participants $(N=20)$, (b) there were no outliers, (c) with the exception of the pre-test, the data was not normally distributed in all tests, as assessed by Q-Q plots and the Shapiro-Wilk test, and (d) the homogeneity of variance was violated in most cases, as assessed by Levene's Test of Homogeneity of Variance.

Table 2. Results of Kruskal-Wallis H tests and One-way ANOVA tests

\begin{tabular}{|l|l|l|}
\hline & Result & Interpretation \\
\hline Pre-test & $F(2.57)=2.006, p=.144$ & NS \\
\hline ES1 & $H(2)=5.631, p=.060$ & NS \\
\hline ES2 & $H(2)=9.833, p=.007$ & $\begin{array}{l}\text { Mean rank scores of groups 1, 2, and 3, were } \\
\text { statistically significantly different }\end{array}$ \\
\hline ES3 & $H(2)=10.938, p=.004$ & $\begin{array}{l}\text { Mean rank scores of groups 1, 2, and 3, were } \\
\text { statistically significantly different }\end{array}$ \\
\hline ES4 & $H(2)=6.777, p=.034$ & $\begin{array}{l}\text { Mean rank scores of groups 1, 2, and 3, were } \\
\text { statistically significantly different }\end{array}$ \\
\hline ES5 & $H(2)=10.380, p=.006$ & $\begin{array}{l}\text { Mean rank scores of groups 1, 2, and 3, were } \\
\text { statistically significantly different }\end{array}$ \\
\hline Delayed post-test & $H(2)=5.816, p=.055$ & NS \\
\hline Note. NS = not statistically significant difference \\
\hline
\end{tabular}

In the pre-test test, where all the assumptions were met, ANOVA testing was conducted. To the other evaluation sheets, the Kruskal-Wallis $\mathrm{H}$ test was used, which is a non- 
parametric test. Even though this test does not require the normal distribution of data, it assumes that the shapes of their distribution are similar in all groups (Corder \& Foreman, 2009; Siegel \& Castellan, 1988), as was the case in the present study. The results of these tests are presented in Table 2.

In those tests where statistically significant differences were noted, post-hoc comparisons were conducted on all possible pairwise contrasts, using the Bonferroni approach (controlling for Type I errors) (Dunn, 1964). It was found that:

- ES2. Group 3 (mean rank score = 25.85) fared better than Group 2 (mean rank score $=15.15),(U=93.00, Z=-2.933, p=.003)$ and the effect size was medium to large $(r=-.46)$. On the other hand, Group 3 and Group 1 did not have statistically significant difference, $(U=$ $186.50, Z=-0.378, p=.706$ ). In addition, Group 1 (mean rank score $=24.90$ ) outperformed Group $2($ mean rank score $=16.10),(U=112.00, Z=-2.409, p=.016)$ and the effect size was medium $(r$ $=-.38)$.

- ES3. Group 3 (mean rank score = 26.00) fared better than Group 2 (mean rank score $=15.00),(U=90.00, Z=-3.156, p=.002)$ and the effect size was large $(r=-.50)$. As in ES2, Group 3 and Group 1 did not have statistically significant difference $(U=160.50, Z=-1.256, p=$ .209). Also, Group 1 (mean rank score $=24.20)$ outperformed Group 2 (mean rank score $=16.80)$, $(U=126.00, Z=-2.086, p=.037)$ and the effect size was medium $(r=-.33)$.

- ES4. Group3 (mean rank score $=24.35$ ) outperformed Group 2 (mean rank score $=16.65),(U=123.00, Z=-2.166, p=.030)$ and the effect size was medium $(r=-.34)$. As in the above evaluation sheets, Group 3 and Group 1 did not have statistically significant difference $(U=$ 192.50, $Z=-0.230, p=.818$ ). Once again, Group 1 (mean rank score $=24.45$ ) outperformed Group2 (mean rank score $=16.55),(U=121.00, Z=-2.236, p=.025)$ and the effect size was medium $(r=-.35)$.

- ES5. Group 3 and Group 2 did not have statistically significant difference $(U=$ 136.00, $Z=-1.776, p=.076)$. On the other hand, Group 1 (mean rank score $=25.93$ ) outperformed Group3 (mean rank score $=15.08),(U=91.50, Z=-3.005, p=0.003)$, and the effect size was medium to large $(r=-.47)$. Finally, Group 1 and Group 2 did not have statistically significant difference $(U=132.50, Z=-1.859, p=.063)$.

Taken together, the above results suggested that:

- All groups had the same initial knowledge level, given that in the pre-test there was no statistically significant difference between them. Therefore, any differences noted in the evaluation sheets can be attributed to the different teaching methods.

- In ES1 (Pollution) and in the delayed post-test, there were no statistically significant differences between the three groups. Therefore, in these cases, the different teaching methods had no effect on the learning outcomes of students.

- In ES2 (Meet recycling bins), in ES3 (What about electronics?), and in ES4 (Do you love our planet?), while groups 1 and 3 did not have statistically significant differences, they both outperformed Group 2.

- In ES5 (Air Pollution), Group 1 outperformed Group 3, but not Group 2. Also, groups 2 and 3 did not have different learning outcomes.

- In total, Group 3 (computer games), outperformed Group 2 (constructivist teaching) in three out of six cases (including the delayed post-test), while these groups had the same results in the other three cases. Also, Group 3 did not have a statistically significant difference with Group 1 (conventional teaching) in five out of six cases.

On the basis of the above, H1 (teaching EFL with the use of computer games produces 
learning outcomes that are similar to those of conventional teaching methods) is confirmed.

Coming to the questionnaire which was administered to students who used the computer games, their positive attitude towards them is evidenced in most of their responses (Table 3). Students liked the games (in general) a lot $(M=4.45, S D=0.83)$ and expressed their desire to use games in other courses as well $(M=4.60, S D=0.99)$. Students also pointed out that they faced no problems in controlling/using the games $(M=4.50, S D=0.95)$ and that they helped them to learn English $(M=4.20, S D=1.06)$. Their opinions regarding the various game features were also very positive (e.g., music $M=4.00, S D=1.17$; characters and graphics $M=4.05, S D=$ 1.00). It has to be noted that students also liked that they worked in pairs $(M=4.60, S D=0.75)$.

Students' positive attitude towards the games was also evident in their responses to the open-ended questions. Some indicative responses were:

"I liked all the units a lot and I also enjoyed working with [name/fellow student]".

"I will never forget these lessons!" playing”.

"It was nice because we were doing our lesson and at the same time we were

On the basis of the above, H2 (students form positive attitudes regarding the use of computer games in the teaching EFL) was also confirmed.

Table 3. Questionnaire's results

\begin{tabular}{|l|c|c|}
\hline Question & $M$ & $S D$ \\
\hline The games were nice. & 4.45 & 0.83 \\
\hline I liked the games' music. & 4.00 & 1.17 \\
\hline I liked the games' 3D characters. & 4.05 & 1.00 \\
\hline The characters' animation was nice. & 3.70 & 1.26 \\
\hline I did not like working with my fellow student.* & 4.60 & 0.75 \\
\hline It was nice that we were playing while studying. & 4.35 & 1.09 \\
\hline I think that I did not learn anything by playing these games. ${ }^{*}$ & 4.20 & 1.06 \\
\hline Using/controlling the games was easy. & 4.50 & 0.95 \\
\hline Learning through games was easy & 4.10 & 1.37 \\
\hline I would like to use games in other courses too. & 4.60 & 0.99 \\
\hline Note. ${ }^{*}=$ question for which its scoring was reversed & & \\
\hline
\end{tabular}

\section{Discussion}

Computer games for teaching EFL are rarely used in mainstream primary school settings. The present study contributes to the knowledge base of this still inadequately documented yet important area, by designing and implementing a project which had as a target group, 10-11-year-old students. During the design of the project, there were reservations regarding the learning outcomes of the three teaching methods, given that most students study English in private evening schools. The data in Table 1 demonstrate, quite clearly, that in all the evaluation sheets (including the pre- and the delayed post-test), students were able to achieve quite high scores, which, probably, indicates a fairly good knowledge of English. This, in turn, probably had an impact on the study's results because it did not allow the differences between groups to be very strong. Indeed, the data analysis revealed that the statistically significant differences between groups varied and that no teaching method was, clearly, better than the rest. This finding is in agreement with previous studies that reported mixed results (e.g., Perrotta et al., 2013). 
On the other hand, it can be argued, with relative certainty, that computer games produced equally good (and in some cases better) learning outcomes compared to the other two methods. On the basis of this result, it can be supported that they can serve as an effective medium for teaching EFL at primary school level. This argument can be backed by students' responses to the questionnaire, given that their views were particularly positive regarding all of the project's aspects. A series reasons that have to do with the games and the teaching method that was followed, may have led to this result.

Students stated that collaboration with their fellow students had a positive impact on their learning and that cooperation with their peers was smooth. Collaboration between peers was the theoretical basis on which the whole project was based. The fact that it worked well, probably led to the active participation of students in the learning process, experimentation and in the common effort to achieve the best possible result (Tolmie et al., 2010). The fact that digital games offer a fertile ground for the exchange of information and ideas, development of cooperative activities, and that they encourage social learning, has been noted in the past (e.g., Mitchell \& Savill-Smith, 2004; Sauvé, Renaud \& Kaufman, 2010).

One has to be reminded that in the games group the teacher's role was minimal; students were highly autonomous and free to follow their own learning pace. Increased learning autonomy when playing educational games is also a factor which operates in parallel with students' cooperation (Fokides, 2017; Prensky, 2001a). In fact, the longer students have control on their own learning process, the better the results (McLoughlin \& Marshall, 2000). So, the fact that in this project there were good learning outcomes, seems to confirm the views of researchers who believe that students with a high degree of autonomy and increased control during the learning process, can achieve positive learning results (Hong, McGee \& Howard, 2000; Mayer \& Moreno, 2003; Nunes, Bryant \& Watson, 2009).

The introduction of computer games in the classroom did not disturb the smooth functioning of it, but, instead, it created a pleasant and fun atmosphere, although students had not previously worked in a similar way. The fun is the dominant element of educational computer games (Mawer \& Stanley, 2011). This was verified and in this work, based on the responses of students to the relevant questions. In turn, the pleasant climate that was formed may have led to increased motivation for learning (Connolly et al., 2012; Malone, 1981; Malone \& Lepper, 1987).

The fun and enjoyment when using the games and the interest of students were probably intensified by the fact that there was a scoring system and added bonuses as "rewards" for their correct answers. Thus, they had immediate feedback for the results of their actions, and, in a way, this encouraged them to try harder. They could also re-play the games if they wished to achieve higher scores. The element of control over the learning process, through ongoing feedback, that computer games allow, has been noted by others (e.g., Larsen et al., 2012)

Students' responses to almost all of the questions regarding the games' features (e.g., music, characters, and graphics) were highly positive. Their replies demonstrated their clear preference to a different kind of a teaching environment (in contrast to conventional textbooks) and this is a strong indication of how welcome is this alternative way of teaching, as other researchers have also noted (Anyaegbu, Ting \& Li, 2012; Prensky, 2007; Wrzesien, Pérez López \& Alcañiz Raya, 2010). Students were able to familiarize themselves with the use of the games quite quickly and they did not experience any problems, confirming their characterization as "digital natives", which indicates their strong relationship with technology (Prensky, 2001b; Whitton, 2007).

The time needed for the development of games was about 150 hours. Although the software used is not considered particularly difficult to learn, the development of educational games by a non-specialist, proved to be a time-consuming process. One might argue that such an effort is not justified if the final outcomes are taken into consideration (Kluge \& Riley, 2008). It 
can also be argued that because the effort was "amateuristic", the inadequacies of the games that were used (both in terms of their implementation and content), might have had a negative impact on the learning outcomes. On the other hand, there are no educational computer games that have been certified for their educational value and the integrity of their content, at least in Greece. Therefore, there is a need for collaboration between educators and computer experts for the production of such games. On the other hand, if we want teachers to become able producers of their own educational games, we need software tools that make the whole process much more agile and intelligent, while reducing the production time (Scacchi, 2012).

\section{Conclusion}

The key finding of the study was that students in the games group achieved the same learning outcomes as the other two groups. Increased interest and motivation were also noted. Although the results are interesting, the study has limitations that have to be taken into account. The sample, although sufficient for statistical analysis, was fairly limited both numerically and geographically. It is therefore quite difficult to generalize the results. Also, due to the short duration of the project, the units that were taught were also limited. The teaching of more units would have enabled a more thorough examination of the research questions. Finally, students may not have been completely honest in their responses to the questionnaire, confusing it with some form of evaluation.

It should be noted that the games were largely "amateuristic"; they were not the outcome of professionals' work. Thus, future research could use games covering more teaching units, having larger sample sizes, wider age groups, and use games that are the result of cooperation between educators and ICT specialists. In addition, future studies may utilize more research tools, such as interviews and observations, that would allow the collection of more detailed research data.

In conclusion, the need to change the way we teach English in mainstream primary school settings and the utilization of innovative teaching methods is almost self-evident. Digital games offer an interesting alternative. However, more research is needed in order to establish their exact impact in teaching.

\section{Statement}

The authors declare no competing interests.

This research did not receive any specific grant from funding agencies in the public, commercial, or not-for-profit sectors.

\section{References}

Anyaegbu, R., Ting, W., \& Li, Y. (2012). Serious game motivation in an EFL classroom in Chinese primary school. Turkish Online Journal of Educational Technology, 11(1), 54-164.

Becker, K. (2005). How are games educational? Learning theories embodied in games. Proceedings of DiGRA 2005 2nd International Conference, Changing Views: Worlds in Play. Vancouver, Canada.

Benavides, E. A. (2001). Interacting in English through games. Profile: Issues in Teachers' Professional Development, 2(1), 6-8. 
Bottino, R. M., Ferlino, L., Ott, M., \& Tavella, M. (2007). Developing strategic and reasoning abilities with computer games at primary school level. Computers \& Education, 49(4), 1272-1286. doi: 10.1016/j.compedu.2006.02.003

Braghirolli, L. F., Ribeiro, J. L., Weise, A.D., \& Pizzolato, M. (2016). Benefits of educational games as an introductory activity in industrial engineering education. Computers in Human Behavior, 58 , 315-324. doi: $10.1016 /$ j.chb.2015.12.063

Connolly, T. M., Boyle, E. A., MacArthur, E., Hainey, T., \& Boyle, J. M. (2012). A systematic literature review of empirical evidence on computer games and serious games. Computers \& Education, 59(2), 661-686. doi: 10.1016/j.compedu.2012.03.004

Connolly, T. M., Stansfield, M., \& Hainey, T. (2011). An alternate reality game for language learning: Arguing for multilingual motivation. Computers \& Education, 57(1), 1389-1415. doi: 10.1016/j.compedu.2011.01.009

Corder, G. W., \& Foreman, D. I. (2009). Nonparametric statistics for non-statisticians: A step-by-step approach. John Wiley \& Sons. doi: 10.1002/9781118165881

Creswell, J. W. (2013). Research design: Qualitative, quantitative, and mixed methods approaches. Sage Publications.

Dickinson, L. (1981). Have you got Mr. Bun the baker? Problems and solutions in the use of games, role play, and simulations. English Language Teaching Journal, 35(4), 381-384.

Dondlinger, M.J. (2007). Educational video game design: a review of the literature. Journal of Applied Educational Technology, 4 (1), 21-31.

Dunn, O. J. (1964). Multiple comparisons using rank sums. Technometrics, 6, 241-252. doi: 10.1080/00401706.1964.10490181

Egenfeldt-Nielsen, S. (2006). Overview of research on the educational use of video games. Digital kompetanse, 1(3), 184-213.

Ertmer, P. A., \& Newby, T. J. (2013). Behaviorism, cognitivism, constructivism: Comparing critical features from an instructional design perspective. Performance Improvement Quarterly, 26(2), 43-71. doi: $10.1002 /$ piq.21143

Escudeiro, P., \& de Carvalho, C. V. (2013). Game-based language learning. International Journal of Information and Education Technology, 3(6), 643-647. doi: 10.7763/IJIET.2013.V3.353

Felicia, P. (Ed.). (2012). Developments in current game-based learning design and deployment. IGI Global.

Fokides, E. (2017). Digital educational games and mathematics. Results of a case study in primary school settings. Education and Information Technologies, 2017.

Garris, R., Ahlers, R., \& Driskell, J. E. (2002). Games, motivation, and learning: A research and practice model. Simulation \& Gaming, 33, 441-467. doi: 10.1177/1046878102238607

Gee, J. P. (2014). What video games have to teach us about learning and literacy. Macmillan.

Gee, J. P. (2009). Deep learning properties of good digital games. In: Serious games: Mechanisms and effects. Routledge Taylor \& Francis Group.

Gee, J. P. (2005). Good video games and good learning. In: Phi Kappa Phi Forum (Vol. 85, No. 2, pp. 3337). The Honor Society of Phi Kappa Phi.

Hong, N. S., McGee, S., \& Howard, B. C. (2000). The effect of multimedia learning environments on wellstructured and ill-structured problem-solving skills. Proceedings of the American Educational Research Association Annual Meeting (Vol. 2000, No. 1).

Ke, F. (2009). A qualitative meta-analysis of computer games as learning tools. Handbook of Research on Effective Electronic Gaming in Education, 1, 1-32. doi: 10.4018/978-1-59904-808-6.choo1

Ke, F. (2008). A case study of computer gaming for math: Engaged learning from gameplay? Computers \& Education, 51(4), 1609-1620. 
Kebritchi, M., \& Hirumi, A. (2008). Examining the pedagogical foundations of modern educational computer games. Computers in Education, 51(4), 1729-1743.

Kirriemuir, J. (2002). The relevance of video games and gaming consoles to the higher and further education learning experience. Techwatch Report.

Kluge, S., \& Riley, L. (2008). Teaching in virtual worlds: Opportunities and challenges. Issues in Informing Science and Information Technology, 5, 2008. doi: 10.28945/3207

Köksal, D. (2004). To kill the blackboard technology in language teaching and learning. The Turkish Online Journal of Educational Technology-TOJET, 3(3), 62-72.

Larsen, L. J. (2012). A new design approach to game-based learning. Journal of Interactive Learning Research, 23(4), 313-323.

Larsen, McClarty, K., Orr, A., Frey, P. M., Dolan, R. P., Vassileva, V., \& McVay, A. (2012). A literature review of gaming in education. Research Report.

Macaro, E., Handley, Z., \& Walter, C. (2012). A systematic review of CALL in English as a second language: focus on primary and secondary education. Language Teaching, 45(1), 1-43.

Malone, T. W. (1981). What makes computer games fun? Byte, 6(12), 258-277.

Malone, T. W., \& Lepper, M.R. (1987). Making learning fun: A taxonomy of intrinsic motivations for learning. In: R.E. Snow \& M. J. Farr (Eds.), Aptitude, learning, and instruction: Vol. 3. Conative and affective process analyses (pp. 223-253). Hillsdale, NJ: Lawrence Erlbaum.

Mayer, R., \& Moreno, R. (2003). Nine ways to reduce cognitive load in multimedia learning. Educational Psychologist, 38(1), 43-52. doi: 10.1207/S15326985EP3801 6

Mawer, K., \& Stanley, G. (2011). Digital play: Computer games and language aims. Peaslake: DELTA Publishing.

McLoughlin, C., \& Marshall, L. (2000). Scaffolding: A model for learner support in an online teaching environment. In: A. Herrmann, \& M. M. Kulski (Eds.), Flexible futures in tertiary teaching. Proceedings of the 9th Annual Teaching Learning Forum. Perth: Curtin University of Technology.

Mitchell, A., \& Savall-Smith, C. (2004). The use of computer and video games for learning. A review of the literature. London: The learning and skills development agency.

Morris, N. O. (2011). Using Technology in the EFL classroom in Saudi Arabia (2011). MA TESOL Collection, Paper 511, 1-50.

Muhanna, W. (2012). Using online games for teaching English vocabulary for Jordanian students learning English as a foreign language. Journal of College Teaching \& Learning (Online), 9, 235. doi: $\underline{10.19030 / \text { tlc.vgi3.7178 }}$

Nunes, T., Bryant, P., \& Watson, A. (2009). Key understandings in mathematics learning. London: Nuffield Foundation.

OfCom, U. K. (2012). Children and parents: media use and attitudes report.

Papastergiou, M. (2009). Digital Game-Based Learning in high school Computer Science education: Impact on educational effectiveness and student motivation. Computers \& Education, 52(1), 1-12. doi: 10.1016/j.compedu.2008.06.004

Perrotta, C., Featherstone, G., Aston, H., \& Houghton, E. (2013). Game-based learning: Latest evidence and future directions. NFER Research Programme: Innovation in Education. Slough: NFER.

Pim, C. (2013). Emerging technologies, emerging minds: digital innovations within the primary sector. In G. Motteram (Ed.), Innovations in learning technologies for English language teaching (pp. 17-42). London: 10 Spring Gardens.

Prensky, M. (2007). Digital game-based learning (Vol. 1). St. Paul, MN: Paragon House. 
Prensky, M. (2004). What kids learn that's positive from playing video games. Simon Fraser University, Surrey Campus Library.

Prensky, M. (2001a). Digital game-based learning. New York/London: McGraw-Hill.

Prensky, M. (2001b). Types of learning and possible game styles. Available at: http://www.marcprensky.com/writing/Prensky\%20\%20Types\%20of\%20Learning\%20and\%20Possible\%20Game\%20Styles.pdf

Sandberg, J., Maris, M., \& De Geus, K. (2011). Mobile English learning: An evidence-based study with fifth graders. Computers \& Education, 47, 1334-1347. doi: 10.1016/j.compedu.2011.01.015

Sauvé, L., Renaud, L., \& Kaufman, D. (2010). Games, simulations, and simulation games for learning. Definitions and distinctions. In D. Kaufman \& L. Sauvé (Eds.), Educational gameplay and simulation environments: case studies and lessons learned (pp. 1-26). Hershey, PA: IGI Global.

Scacchi, W. (2012). The future of research in computer games and virtual world environments. Irvine, CA: University of California.

Shute, V. J., Rieber, L., \& Van Eck, R. (2011). Games . . . and . . learning. In: R. Reiser \& J. Dempsey (Eds.), Trends and issues in instructional design and technology, 3rd Edition, (pp. 321-332). Upper Saddle River, New Jersey: Pearson Education Inc.

Siegel, S., \& Castellan Jr, N. J. (1988). Nonparametric statistics for the behavioral sciences. New York: Mcgraw-Hill.

Squire, K. (2005). Changing the game: What happens when video games enter the classroom. Innovate: Journal of Online Education, 1(6).

Sundqvist, P., \& Sylvén, L. K. (2014). Language-related computer use: Focus on young L2 English learners in Sweden. ReCALL, 26(01), 3-20. doi: 10.1017/So958344013000232

Sylven, L. K., \& Sundqvist, P. (2012). Gaming as extramural English L2 learning and L2 proficiency among young learners. Cambridge University Press, 24(3), 302-321. doi: 10.1017/So95834401200016X

Tolmie, A. K., Topping, K. J., Christie, D., Donaldson, C., Howe, C., Jessiman, E., ... \& Thurston, A. (2010). Social effects of collaborative learning in primary schools. Learning and Instruction, 2O(3), 177-191. doi: 10.1016/j.learninstruc.2009.01.005

Ulicsak, M., \& Williamson, B. (2011). Computer games and learning: a handbook. London, Futurelab.

Whitton, N. (2007). An investigation into the potential of collaborative computer game-based learning in higher education. Doctoral dissertation. Napier University.

Wrzesien, M., Pérez López, D., \& Alcañiz Raya, M. (2010). Learning ecology issues of the Mediterranean sea in a virtual aquatic world - pilot study. Journal of Cyber Therapy \& Rehabilitation, 3(3), 255260.

Wu, W. H., Chiou, W. B., Kao, H. Y., Hu, C. H. A., \& Huang, S. H. (2012). Re-exploring game-assisted learning research: the perspective of learning theoretical bases. Computers \& Education, 59(4), 1153-1161.

Yolageldili, G. (2011). Effectiveness of using games in teaching grammar to young learners. Elementary Education Online, 1O(1), 219-229. 